\title{
Financial Performance Analysis of NBFC-MFIs in India using TOPSIS and IV-TOPSIS
}

\author{
Priyanka Roy \\ Department of Management Studies, \\ National Institute of Technology Silchar, Assam, India. \\ Corresponding author: priyanka_rs@mba.nits.ac.in \\ Binoti Patro \\ Department of Management Studies, \\ National Institute of Technology Silchar, Assam, India. \\ E-mail: binotipatro@mba.nits.ac.in
}

(Received on May 29, 2021; Accepted on September 22, 2021)

\begin{abstract}
The policymakers around the globe have been emphasizing on financial inclusion in line with sustainable development goals 2030 of the United Nations. Developing countries are still behind in ensuring greater financial inclusion especially for women. While banks are the apex financial institutions in any country, microfinance institutions proved to be promising in advancing financial inclusion because of its better reach to women in remote areas. Thus in a country like India, the outreach and sustainability of microfinance institutions is of utmost importance. This paper aims to rank the performance of microfinance institutions listed by Reserve Bank of India on the basis of their outreach, sustainability, quality and efficiency. The ranking is done separately for five years (2014-15 to 2018-19) using Technique for Order of Preference (TOPSIS) method while overall ranking and benchmarking for five years has been done using interval valued TOPSIS (IV-TOPSIS) method. The robustness of the study has been checked through sensitivity analysis. The overall results portray Satin Creditcare Network Limited as the best performing NBFC-MFI while BWDA Finance Limited as the worst performer for the combined period of 5 years
\end{abstract}

Keywords- Benchmarking, Financial performance, Microfinance, TOPSIS, Sensitivity analysis.

\section{Introduction}

Inclusive growth is critical for the overall development of any economy and financial inclusion is a major determinant of an inclusive economic system. Policymakers around the globe have been emphasizing on a well-developed inclusive financial system for faster economic growth owing to its ability in ensuring better channelization of resources into productive uses from every section of the society. In a developing region like India with a huge population, microfinance has provided promising results in better outreach to the poor in providing formal financial services which was otherwise difficult with mainstream banking structure. The gender gap in financial inclusion in developing economies is consistent at 9 per cent (Demirgüç-Kunt et al., 2013) which obstructs faster and sustainable development. Microfinance institutions (MFIs) are capable of closing this gender gap in financial inclusion as it has better outreach to the poor women helping in their empowerment and poverty alleviation.

While outreach is important, Rosenberg (2009) suggests that sometimes rapid expansion of MFIs can cost them their sustainability especially during early years. Hence microfinance institutions also have a role to ensure its sustainability and focus on designing products and building systems efficiently. Usually, financial sustainability is used as a measure to judge the success of an MFI 
(Nadiya et al., 2012) but it is important that a MFI's performance should be judged in a comprehensive way based on multiple factors like outreach, sustainability and efficiency. The role of MFIs in ensuring economic growth in India through inclusive financial systems triggers interest among practitioners, academicians and regulators to analyze the performance of microfinance institutions. The importance of performance analysis lie with adopting proactive measures in removing existing bottlenecks in the system and also in differentiating between good and underperforming MFIs for a more fact-based decisions by funders (Sinha and Pandey, 2019). However, performance analysis of individual MFIs gives partial knowledge since it cannot clearly gauge the relative performance of an individual MFI compared to the overall performance of the microfinance sector. This presses the need for a comparative performance evaluation. The ranking of different MFIs can help provide a benchmark of financial performance enabling assessment of strengths and improvement of weaknesses by companies against the benchmark performance. This would also assist investors in the decision-making of their funding allocation to viable and efficient MFIs.

While most of the existing literature has focused on monitoring the performance of financial institutions like banks, there is a dearth of study focusing on analyzing and comparing performance of microfinance institutions. The gap also remains in examining performance of MFIs based only on efficiency indicators which is not sufficient in providing a complete picture. This presses the need for a multi-faceted perspective in performance analysis. The current paper tries to fill this gap by providing a comprehensive outlook on different performance indicators of MFIs and ranks them not only for individual time periods but also for an overall time period of 5 years. To the best of our knowledge, this has not been addressed before in the microfinance literature. The performance analysis over time would help MFIs in addressing the trade-offs between their outreach and sustainability. Additionally, the paper uses objective weighing methodology for the different performance indicators using CRITIC method which adds a feather to the existing body of knowledge where majority of the studies use subjective weighing methods. This is further highlighted in the literature review and methodology section. Further, sensitivity analysis has been performed with four different sets of weights for robustness check.

MFIs in India are registered as different entities ${ }^{1}$ like Non-governmental Organization MFIs (NGO-MFIs), Cooperatives, Section-25 companies (not-for-profit), For-profit NBFCs (NonBanking Financial Institutions) and NBFC-MFIs. Microfinance institutions dispersed across the country under various registering authorities makes it difficult to gauge an exact reliable estimate of the total number of MFIs (Sinha and Pandey, 2019). The overview of microfinance industry depicts a growth of $16 \%$ from December 2019 to December 2020 with banks witnessing the highest year-over-year (Y-o-Y) growth followed by NBFC-MFIs ${ }^{2}$. NBFC-MFIs are also the second highest contributor (33\%) towards disbursed amount in the quarter October-December, 2020 (OND’20). Moreover trends in average ticket size show NBFC-MFIs witnessing highest Yo-Y growth of $15 \%$ from OND'19 to OND'20. So, this paper attempts to analyze the performance of NBFC-MFIs registered with the Reserve Bank of India (RBI) listed in RBI's website (as on January 31, 2021) for a combined period of five years (2014-15 to 2018-19). For the performance analysis, ranking and benchmarking, Multiple Criteria Decision Making (MCDM) approach has been used (TOPSIS and IV-TOPSIS) which is discussed in the methodology section.

\footnotetext{
${ }^{1}$ Details of legal structure of MFIs can be found in Sa-Dhan's report (2006): "Existing Legal and Regulatory Framework for the Microfinance Institutions in India: Challenges and Implications".

${ }^{2}$ Microfinance Pulse report: Volume VIII (April, 2021) by Equifax and SIDBI.
} 
The selection of MCDM approach for problem solving depends on factors like ease of use, logical soundness, flexibility, comprehensiveness, rationality and so on. TOPSIS has been advocated to have many of these advantages by different researchers (Shih et al., 2007; Roszkowska, 2011) as compared to other MCDM methods. There are numerous applications of TOPSIS owing to its usability as one practical tool for evaluating and ranking alternatives. This makes TOPSIS one of the most commonly used methods in diverse areas like human resource, production and manufacturing, transportation, management etc. Since TOPSIS is a simple model in terms of computation, applicability and understanding, it deemed suitable for this study with potential readers and academicians from non-mathematical backgrounds as well. However, as observed by the authors, one of the limitations of using TOPSIS in other studies lie with using subjective weights through methods like Analytical Hierarchy Process (AHP) which may create biasness. This limitation has been addressed in this study through application of CRITIC for determining weights of the performance indicators while using TOPSIS. Thus, CRITIC and TOPSIS together constitute a strong method to evaluate and rank the performance of MFIs. The overall paper is divided into 5 sections. The study started with a brief introduction in section 1 followed by literature review in section 2 . Thereafter the methodology is discussed in section 3 . Section 4 deals with the findings and discussion while section 5 concludes the study.

\section{Literature Review}

Microfinance institutions are better equipped in targeting poor individuals as compared to banks by providing loans at small scale with easy collateral requirements. This is instrumental in poverty reduction and enhancing economic strength of a nation. A recent study by Ngong et al. (2021) validates long term negative relationship between micro-financial inclusion and poverty alleviation. The importance of microfinance in poverty reduction and economic growth has been highlighted in various other studies. (Lacalle-Calderón et al., 2015; Ghouse, 2019; Mushtaq and Bruneau, 2019; Abrar et al., 2021). Microfinance sector in India has an impressive growth in reaching clients through Self-Help Groups $(\mathrm{SHGs})^{3}$ but capital procurement is important for maintaining this growth. In fact, high cost of service delivery to the poor makes sustainability of operations challenging (Hermes and Lensink, 2007). Some studies argue the possibility of simultaneous achievement of sustainability and outreach (Louis et al., 2013; Quayes and Joseph, 2017) while others postulate the trade-off between reaching the poor while ensuring financial sustainability (Bedecarrats et al., 2009; Awaworyi Churchill, 2020). Monitoring performance of MFIs over time proves useful in addressing constraints of the trade-off.

Studies on performance analysis of microfinance institutions are diverse. A literature review study by Hermes and Hudon (2018) found majority of existing studies focusing on efficiency measures of MFIs. Mustafa and Saat (2013) also reviewed literatures on existing performance measurement criteria used for examining MFIs and built a new multifaceted performance measurement approach. Chattopadhyay and Mitra (2017) prepared a performance measurement framework considering the challenges of analyzing microfinance performance due to its dual objective of outreach and sustainability. Bartual Sanfeliu et al. (2013) also proposed a multicriterion methodology on goal programming considering different financial performance indicators for MFIs. Another multi-criteria method for performance analysis has been proposed based on goal programming (Cervelló-Royo et al., 2019) considering social performance besides outreach and financial performance. Considering social and financial performance along with governance, Bardhan et al. (2021) found interrelationship among these three factors in

3Further reading: "Bharat Microfinance Report, 2020” by Sa-Dhan; “Microfinance Pulse Report, 2019” by SIDBI. 
determining overall performance of MFIs. Ghose et al. (2018) compared financial and social performance of MFIs based on their legal status and found that NGO-MFIs performs financially better as compared to NBFCs but there is no distinction among these two types of MFIs in terms of social performance. Ferro-Luzzi and Weber (2006) have conducted performance analysis of 45 microfinance institutions using factor analysis. In another study Shafi and Reddy (2017) have analyzed financial performance of Indian microfinance institutions through an exploratory research method and found decent performance by MFIs in five years' time span.

Yaron (1994) advocated outreach and sustainability as main factors in determining success of rural financial institutions and recommended breadth of outreach and subsidy development index as measures to assess RFIs performance. De Crombrugghe et al. (2008) studied self-sustainability determinants of Indian MFIs with three set of performance indicators which include financial and operational self-sustainability, repayment of loans and cost. Another study examined factors determining financial sustainability of MFIs in India (Dutta and Das, 2014) and found portfolio quality and capital management as important determinants. The determinants of social worth of MFIs have been studied by Navajas et al. (2000) in terms of depth, cost and worth to users and length, breadth and scope of output. Pal Narwal et al. (2015) used financial ratios like return on assets and equity for measuring performance and determined factors affecting these performance indicators. They found size and spread of total assets to be significant determinant of performance. Using measures of outreach and financial performance, African Greenfield MFIs were benchmarked against other African MFIs (Cull et al., 2015) and faster growth and profitability of Greenfield microfinance been observed through regression analysis. Another study was done on productivity of Indian MFIs (Ambarkhane et al., 2018) using Malmquist productivity index using indicators of outreach and sustainability for input-output variables.

Most of the existing studies focused on analyzing determinants of performance of MFIs as well as considered different indicators of sustainability, efficiency and outreach but there is hardly any study which benchmarks through ranking of MFIs' performance. Benchmarking is a useful tool enabling companies to assess their performance and improve their weaknesses by comparing with market leaders (Saunders et al., 2007). There are studies related to performance ranking of different private or public sector banks (Ho and Wu, 2006; Amile et al., 2013; Gümrah, 2016) but almost none in the microfinance sector. This paper tries to rank 20 NBFC-MFIs in India among the ones registered under RBI. The paper uses Multi-Criteria Decision Making (MCDM) approach- TOPSIS method for ranking the MFIs in different years and Interval-Valued TOPSIS (IV-TOPSIS) to rank the MFIs in a comprehensive manner combining five years data. A similar study using these MCDM approaches have been carried out for ranking private sector banks (Gupta et al., 2020). However, they have used Analytical Hierarchy Process (AHP) for assigning subjective weights to each of the performance indicators. Saad et al. (2019) measured sustainability of MFIs in Pakistan by developing an index using TOPSIS assigning equal weights. This paper uses objective weighting using Criteria Importance through Inter-criteria Correlation (CRITIC) method.

\section{Methodology \\ 3.1 Data and variables}

The literatures studied clearly portray the multidimensionality of microfinance performance. A single factor cannot decide the performance of a microfinance institution. This paper has attempted to capture four broad factors-outreach, quality, sustainability and efficiency-to measure the performance of selected MFIs. The indicators to measure outreach, sustainability and 
efficiency are not unanimous in literatures either. In this paper the indicators have been selected which are commonly adopted and used ${ }^{4}$. The variables for outreach, sustainability and efficiency are explained in Table 1. A total of 7 indicators have been used which serve as the attributes/criteria in the TOPSIS method.

As discussed, the paper analyzes performance of NBFC-MFIs listed by Reserve Bank of India. The data for different performance indicators have been collected from Microfinance Information eXchange (MIX market) by Centre for Financial Inclusion. Out of 96 NBFC-MFIs listed in RBI's website, the complete information regarding annual data for five years and all the selected indicators could be found for only 20 NBFC-MFIs and rest were excluded due to missing data. So this paper has attempted to conduct performance analysis for those 20 NBFC-MFIs from 2014 to 2018.

Table 1. Indicators of performance.

\begin{tabular}{|c|c|c|c|}
\hline Performance measure & Indicator (Performance criteria) & Criteria type & Definition* \\
\hline $\begin{array}{l}\text { Outreach- Number of } \\
\text { clients served }\end{array}$ & $P_{1}$ - Number of active borrowers & Beneficial & $\begin{array}{l}\text { "Number of individuals currently having an } \\
\text { outstanding loan balance with the financial } \\
\text { institution or are primarily responsible for } \\
\text { repaying any portion of the gross loan portfolio. } \\
\text { Individuals having multiple loans with a } \\
\text { financial institution is counted as a single } \\
\text { borrower" }\end{array}$ \\
\hline \multirow{2}{*}{$\begin{array}{l}\text { Financial } \\
\text { Sustainability- } \\
\text { Profitability of MFIs to } \\
\text { maintain and expand its } \\
\text { services }\end{array}$} & $\mathrm{P}_{2}-$ Return on Assets (ROA) & Beneficial & $\begin{array}{l}\text { "(Net Operating Income - Taxes) / Average } \\
\text { Total Assets" }\end{array}$ \\
\hline & $\mathrm{P}_{3^{-}}$Return on Equity (ROE) & Beneficial & $\begin{array}{l}\text { "(Net Operating Income - Taxes) / Average } \\
\text { Total Equity" }\end{array}$ \\
\hline $\begin{array}{l}\text { Quality- Loan } \\
\text { repayment }\end{array}$ & $\begin{array}{l}\mathrm{P}_{4}-\text { Portfolio at risk }>30 \text { days } \\
\text { (PAR) }\end{array}$ & Non-beneficial & $\begin{array}{l}\text { "Outstanding balance, portfolio overdue > } 30 \\
\text { Days + renegotiated portfolio / Gross Loan } \\
\text { Portfolio" }\end{array}$ \\
\hline \multirow{3}{*}{$\begin{array}{l}\text { Efficiency- Ability of } \\
\text { MFIs to control } \\
\text { operating cost }\end{array}$} & $\begin{array}{l}\mathrm{P}_{5^{-}} \text {Operational self-sufficiency } \\
(\mathrm{OSS})\end{array}$ & Beneficial & $\begin{array}{l}\text { "Financial Revenue / (Financial Expense + Net } \\
\text { Impairment Loss + Operating Expense)" }\end{array}$ \\
\hline & $\mathrm{P}_{6^{-}}$Cost per borrower & Non-beneficial & $\begin{array}{l}\text { "Operating Expense / Average Number of } \\
\text { Active Borrowers" }\end{array}$ \\
\hline & $\mathrm{P}_{7}$-Operating expense ratio & Non-beneficial & $\begin{array}{l}\text { "Operating Expense / Average Gross Loan } \\
\text { Portfolio" }\end{array}$ \\
\hline
\end{tabular}

*Definitions of the indicators are taken from MIX

\subsection{Determination of Objective Weights- CRITIC}

The analysis of performance through ranking of MFIs by TOPSIS method requires weighing of selected criteria. Weight determination is a difficult task as it involves careful decision making subject to the risk of biasness. Thus, objective weight assignment without any decision maker's intervention is important for unbiased ranking. In this paper "CRiteria Importance Through Intercriteria Correlation (CRITIC)" method as proposed by Diakoulaki et al. (1995) is applied in assigning objective weights to the performance indicators. This method emphasizes on 'notion of conflict' which is a necessary consideration in inter-firm comparisons because of the presence of high correlation between financial ratios in general. "The computational results illustrate the advantages of CRITIC, over other techniques aiming at an objective resolution of multi-criteria decision problems" as pointed in their work. Following their methodology the weights have been derived for analysis in this study.

${ }^{4}$ Most of the indicators are taken from CGAP Technical guide (2009) on "Measuring Results of Microfinance Institutions- Minimum Indicators that Donors and Investors Should Track". 
Before the assignment of weights a decision matrix $D(n \times m)$ is constructed containing $\mathrm{n}$ alternatives (MFIs) $A_{i}(i=1,2, \ldots, n)$ and m performance criteria $P_{j}(j=1,2, \ldots, m)$ :

$$
\begin{aligned}
& \begin{array}{llll}
P_{1} & P_{2} & \ldots & P_{m},
\end{array} \\
& D\left(x_{i j}\right)=\begin{array}{c}
A_{1} \\
A_{2} \\
\vdots \\
A_{n}
\end{array}\left[\begin{array}{cccc}
x_{11} & x_{12} & \cdots & x_{1 m} \\
x_{21} & x_{22} & \cdots & x_{2 m} \\
\vdots & \vdots & \ddots & \vdots \\
x_{n 1} & x_{n 2} & \cdots & x_{n m}
\end{array}\right] .
\end{aligned}
$$

Five decision matrices have been constructed for each year from 2014-15 to 2018-195.

Steps for assigning weights follow:

Step 1: Calculation of normalized decision matrix- The decision matrix is normalized using the formula-

$$
x_{i j}^{N}=\frac{x_{i j}-x_{j}^{\text {worst }}}{x_{j}^{\text {best }}-x_{j}^{\text {worst }}}
$$

where,

$\mathrm{x}_{\mathrm{j}}^{\text {best }}=$ maximum value for beneficial criteria or minimum value for non-beneficial criteria,

$x_{j}^{\text {worst }}=$ minimum value for beneficial criteria or maximum value for non-beneficial criteria.

Step2: Calculation of standard deviation $\sigma_{j}$ for each criterion that quantifies the contrast intensity of the corresponding criterion.

Step 3: Construction of a symmetric matrix $R(m \times m)$ with elements $r_{j k}$ which is the linear correlation coefficients between the criteria vectors $x_{j}$ and $x_{k}$. The more the discordance between the scores of alternatives in criteria $j$ and $k$, the lower is the value $r_{j k}$.

Step 4: Calculation of measure of conflict created by criterion $\mathrm{j}$ with respect to the decision situation defined by the rest of the criteria. The measure of conflict is measured using the formula:

$$
\sum_{k=1}^{m}\left(1-r_{j k}\right) \text {. }
$$

Step 5: Determination of quantity of information $C_{j}$ in relation to each criterion through the following multiplicative aggregation formula:

$$
C_{j}=\sigma_{j} * \sum_{k=1}^{m}\left(1-r_{j k}\right) \text {. }
$$

\footnotetext{
${ }^{5}$ For each year 20 alternatives (NBFC-MFIs) have been considered for analysis with the exception of 2018-19, where 18 alternatives have been analyzed. It was because of missing data for two alternatives for some of the performance criteria.
} 
The higher the value of $C_{j}$, the larger is the dissemination of information from a criterion implying its higher relative importance in the decision making.

Step 6: Lastly, the values are normalized to unity for obtaining the final objective weights using the formula:

$$
w_{j}=\frac{C_{j}}{\sum_{k=1}^{m} C_{k}} .
$$

For this study weights have been calculated for each year and simple arithmetic average of the weights have been considered as final weights for performance analysis to have a uniform weighing strategy. The weights obtained are shown in Table 2.

Table 2. Objective weights for performance analysis.

\begin{tabular}{|c|c|c|c|c|c|c|}
\hline \multirow{2}{*}{ Criteria $\left(\mathbf{P}_{\mathbf{j}}\right)$} & \multicolumn{7}{|c|}{ Weights (\%) } & $\mathbf{2 0 1 8}$ & Final weights $\left(\mathbf{w}_{\mathbf{j}}\right)$ \\
\cline { 2 - 7 } & $\mathbf{2 0 1 4}$ & $\mathbf{2 0 1 5}$ & $\mathbf{2 0 1 6}$ & $\mathbf{2 0 1 7}$ & 14 & 29 \\
\hline $\mathbf{P}_{\mathbf{1}}$ & 21 & 25 & 20 & 48 & 13 & 10 \\
\hline $\mathbf{P}_{\mathbf{2}}$ & 11 & 9 & 14 & 4 & 11 & 11 \\
\hline $\mathbf{P}_{\mathbf{3}}$ & 11 & 14 & 13 & 6 & 24 & 18 \\
\hline $\mathbf{P}_{\mathbf{4}}$ & 27 & 15 & 18 & 5 & 14 & 10 \\
\hline $\mathbf{P}_{\mathbf{5}}$ & 8 & 9 & 12 & 7 & 12 & 12 \\
\hline $\mathbf{P}_{\mathbf{6}}$ & 12 & 16 & 12 & 6 & 12 & 10 \\
\hline $\mathbf{P}_{\mathbf{7}}$ & 10 & 12 & 11 & 100 & 100 & 100 \\
\hline Total & 100 & 100 & 100 & & & \\
\hline
\end{tabular}

Source: Authors' calculations

\subsection{Ranking Performances of NBFC-MFIs-Technique for Order of Preference by Similarity to an Ideal Solution (TOPSIS)}

TOPSIS is a traditional Multi-Criteria Decision Making method originally developed by Hwang and Yoon (1981). This method is based on the concept of having the shortest Euclidean distance of a chosen alternative from a positive ideal solution and longest distance from a negative ideal solution.

For conducting TOPSIS, firstly the decision matrix $D=\left[x_{i j}\right]$ is normalized to obtain a normalized decision matrix $Z=\left[Z_{i j}\right]$. The normalization is done using the formula

$$
z_{i j}=\frac{x_{i j}}{\sqrt{\sum_{i=1}^{n} x_{i j}^{2}}}(i=1,2, \ldots, n ; j=1,2, \ldots, m) \text {. }
$$

After normalization of the decision matrix to have performance points in a uniform scale, the weighted normalized matrix $V_{i j}$ is formed by multiplying each element of the matrix $N=\left[n_{i j}\right]$ with the calculated weights $w_{j}$ :

$$
V_{i j}=\left[\begin{array}{cccc}
w_{1} z_{11} & w_{2} z_{12} & \cdots & w_{m} z_{1 m} \\
w_{1} z_{21} & w_{2} x_{22} & \cdots & w_{m} x_{2 m} \\
\vdots & \vdots & \ddots & \vdots \\
w_{1} z_{n 1} & w_{2} z_{n 2} & \cdots & w_{m} z_{n m}
\end{array}\right] .
$$

Next the ideal best value $V_{j}^{+}$and ideal worst value $V_{j}^{-}$is calculated as:

$V_{j}^{+}=\left\{\left(\sum_{i}^{\max } V_{i j} J\right),\left(\sum_{i}^{\text {min }} V_{i j} J^{\prime}\right) \mid i=1,2, \ldots, n\right\}=\left\{V_{1}^{+}, V_{2}^{+}, V_{3}^{+}, \ldots, V_{m}^{+}\right\}$,

$V_{j}^{-}=\left\{\left(\sum_{i}^{\min } V_{i j} J\right),\left(\sum_{i}^{\max } V_{i j} J^{\prime}\right) \mid i=1,2, \ldots, n\right\}=\left\{V_{1}^{-}, V_{2}^{-}, V_{3}^{-}, \ldots, V_{m}^{-}\right\}$. 
Here, $J$ and $J^{\prime}$ are associated with beneficial and non-beneficial criteria respectively. The above two equations imply that for ideal best value associated with a criterion, the maximum value is taken as $V_{j}^{+}$if it is associated with a beneficial criteria while minimum value is taken as $V_{j}^{+}$if it is associated with non-beneficial criteria. In case of ideal worst, reverse judgment is followed wherein minimum value for beneficial criteria and maximum value for non-beneficial criteria are taken $\operatorname{as} V_{j}^{-}$

The next step involves calculating the Euclidean distance from ideal best $\left(S^{+}\right)$and ideal worst $\left(S^{-}\right)$solutions for each alternative:

$$
\begin{aligned}
& S_{i}^{+}=\sqrt{\sum_{j=1}^{m}\left(V_{i j}-V_{j}^{+}\right)^{2}}, i=1,2, \ldots, m ; j=1,2, \ldots, n, \\
& S_{i}^{-}=\sqrt{\sum_{j=1}^{m}\left(V_{i j}-V_{j}^{-}\right)^{2}}, i=1,2, \ldots, m ; j=1,2, \ldots, n .
\end{aligned}
$$

Finally, the closeness coefficients $\left(C_{i}\right)$ are calculated which are considered as the performance scores of the alternatives:

$$
C_{i}=\frac{S_{i}^{-}}{S_{i}^{+}+S_{i}^{-}}
$$

\begin{tabular}{|c|c|c|c|c|c|c|c|c|c|c|}
\hline \multirow{2}{*}{$\begin{array}{l}\text { Alternatives } \\
\text { (NBFC-MFIs) } \\
\text { [Abbreviations] }\end{array}$} & \multicolumn{2}{|c|}{ 2014-15 } & \multicolumn{2}{|c|}{ 2015-16 } & \multicolumn{2}{|c|}{ 2016-17 } & \multicolumn{2}{|c|}{ 2017-18 } & \multicolumn{2}{|c|}{ 2018-19 } \\
\hline & $C_{i}$ & Rank & $C_{i}$ & Rank & $C_{i}$ & Rank & $C_{i}$ & Rank & $C_{i}$ & Rank \\
\hline Adhikar & 0.470011 & 15 & 0.473874 & 7 & 0.353762 & 5 & 0.405378 & 8 & 0.319151 & 10 \\
\hline Agora & 0.367896 & 19 & 0.414985 & 19 & 0.292639 & 14 & 0.268116 & 18 & 0.236505 & 16 \\
\hline Arohan & 0.561629 & 4 & 0.559058 & 3 & 0.420526 & 2 & 0.546401 & 2 & 0.62828 & 2 \\
\hline ASA & 0.472696 & 14 & 0.467747 & 10 & 0.344991 & 8 & 0.468436 & 4 & 0.408608 & 3 \\
\hline Asomi & 0.463685 & 17 & 0.440553 & 18 & 0.314582 & 11 & 0.368077 & 11 & 0.298618 & 11 \\
\hline Belstar & 0.510861 & 6 & 0.484298 & 6 & 0.35523 & 4 & 0.445558 & 5 & 0.362371 & 6 \\
\hline BWDA & 0.292238 & 20 & 0.037438 & 20 & 0.224175 & 20 & 0.382503 & 10 & 0.269628 & 13 \\
\hline Chaitanya & 0.472974 & 13 & 0.458467 & 13 & 0.227722 & 19 & 0.199711 & 19 & 0.214143 & 18 \\
\hline Fusion & 0.520348 & 5 & 0.527628 & 5 & 0.297631 & 13 & 0.396973 & 9 & 0.368868 & 5 \\
\hline IDF & 0.474279 & 12 & 0.450923 & 15 & 0.326521 & 9 & 0.319656 & 15 & 0.247392 & 14 \\
\hline Madura & 0.568194 & 3 & 0.529339 & 4 & 0.410033 & 3 & 0.470886 & 3 & 0.361321 & 7 \\
\hline M-Power & 0.482284 & 10 & 0.46749 & 11 & 0.244428 & 18 & 0.127932 & 20 & 0.221179 & 17 \\
\hline Pahal & 0.485471 & 7 & 0.458077 & 14 & 0.262824 & 17 & 0.300985 & 16 & 0.325974 & 9 \\
\hline Prayas & 0.484612 & 8 & 0.447345 & 16 & 0.311907 & 12 & 0.360451 & 12 & 0.276838 & 12 \\
\hline Saija & 0.47753 & 11 & 0.465923 & 12 & 0.271582 & 16 & 0.347128 & 13 & - & - \\
\hline Satin & 0.948475 & 1 & 0.958287 & 1 & 0.673341 & 1 & 0.693956 & 1 & 0.725326 & 1 \\
\hline Sonata & 0.600983 & 2 & 0.569886 & 2 & 0.318277 & 10 & 0.274359 & 17 & 0.237624 & 15 \\
\hline Svasti & 0.457358 & 18 & 0.440604 & 17 & 0.282411 & 15 & 0.337088 & 14 & - & - \\
\hline Uttarayan & 0.466459 & 16 & 0.468464 & 9 & 0.351369 & 6 & 0.413967 & 6 & 0.332406 & 8 \\
\hline Village fin & 0.48305 & 9 & 0.46891 & 8 & 0.35108 & 7 & 0.406166 & 7 & 0.375947 & 4 \\
\hline
\end{tabular}

Table 3. Closeness coefficients and ranks of the alternatives for each year.

Source: Authors' calculations

Based on the performance scores, the alternatives are ranked in descending order implying that a higher closeness coefficient value corresponds to a better alternative choice. Table 3 summarizes the rank of the alternatives with their closeness coefficients. 


\subsection{Ranking Performances of NBFC-MFIs for Cumulative 5 Years-Interval-Valued TOPSIS (I-V TOPSIS)}

For the exercise of benchmarking and evaluating performances of the NBFC-MFIs for the collective 5 years period, Interval-Valued TOPSIS is used. The traditional method of TOPSIS enables in solving a problem of multi-criteria decision having 'crisp' numeric values. Thus interval extension of TOPSIS algorithm can be used for solving MCDM problem with interval data (Jahanshahloo et al., 2009). The method is almost similar to TOPSIS save the decision matrix which has elements with intervals. Following Mathew and Thomas (2019), IV-TOPSIS have been applied to this study.

Considering a decision matrix with interval valued elements $\left[X_{i j}^{L}, X_{i j}^{U}\right]$ with $\mathrm{m}$ alternatives and $\mathrm{n}$ criteria where, $i \in\{1,2, \ldots, m\}$ and $j \in\{1,2, \ldots, n\}$ the first step involves constructing a normalized decision matrix $\left[N_{i j}^{L}, N_{i j}^{U}\right]$ such that:

$$
N_{i j}^{L}=\frac{x_{i j}^{L}}{\sqrt{\sum_{i=1}^{m}\left\{\left(x_{i j}^{L}\right)^{2}+\left(x_{i j}^{U}\right)^{2}\right\}}} \text { and } N_{i j}^{U}=\frac{x_{i j}^{U}}{\sqrt{\sum_{i=1}^{m}\left\{\left(x_{i j}^{L}\right)^{2}+\left(x_{i j}^{U}\right)^{2}\right\}}} \text {. }
$$

The decision matrix with interval values is formed by considering the minimum and maximum values of the criteria for each alternative from years 2014 to $2018^{6}$. Then, the weighted normalized interval valued decision matrix $\left[v_{i j}^{L}, v_{i j}^{U}\right]$ is calculated where,

$$
v_{i j}^{L}=W_{j} N_{i j}^{L} \text { and } v_{i j}^{U}=W_{j} N_{i j}^{U} .
$$

The weights considered for IV-TOPSIS are same as calculated for TOPSIS before (Table 2). After the calculation of weighted normalized matrix, the positive and negative solutions are calculated as

$$
\begin{aligned}
& A^{+}=\left\{\left(v_{1}^{+}, v_{2}^{+}, \ldots v_{n}^{+}\right)\right\}=\left\{\left(\max _{i} v_{i j}^{U} \mid j \in B\right),\left(\min _{i} v_{i j}^{L} \mid j \in N\right)\right\}, \\
& A^{-}=\left\{\left(v_{1}^{-}, v_{2}^{-}, \ldots v_{n}^{-}\right)\right\}=\left\{\left(\min _{i} v_{i j}^{L} \mid j \in B\right),\left(\max _{i} v_{i j}^{U} \mid j \in N\right)\right\} .
\end{aligned}
$$

$B$ and $N$ are associated with beneficial criteria non-beneficial criteria, respectively. Thereafter, Euclidean distances are calculated for separation measure of each alternative from the positive ideal solution $\left(S_{i}^{+}\right)$and negative ideal solution $\left(S_{i}^{-}\right)$. The separation measures are calculated as

$$
\begin{aligned}
& S_{i}^{+}=\sqrt{\sum_{j \in B}\left(v_{i j}^{L}-v_{j}^{+}\right)^{2}+\sum_{j \in N}\left(v_{i j}^{U}-v_{j}^{+}\right)^{2}}, \\
& S_{i}^{-}=\sqrt{\sum_{j \in B}\left(v_{i j}^{U}-v_{j}^{-}\right)^{2}+\sum_{j \in N}\left(v_{i j}^{L}-v_{j}^{-}\right)^{2}} .
\end{aligned}
$$

The final step involves in measuring the values of relative closeness to the ideal solution.

$$
R_{i}=\frac{S_{i}^{-}}{S_{i}^{+}+S_{i}^{-}} \quad i \in\{1,2,3, \ldots, m\} \text { and } 0 \leq R_{i} \leq 1 \text {. }
$$

${ }^{6}$ Since there are 18 alternatives for the year 2018-19 due to missing data as stated earlier, the final ranking and evaluation is done for those 18 alternatives. 
Based on the values of $R_{i}$ ranking is done such that an alternative with the highest relative closeness value is placed at top rank while that with the lowest closeness value is placed at the bottom. The final ranking with the $R_{i}$ values are shown in Table 4 .

Table 4. Closeness coefficients and ranks of the alternatives for the combined period of 5 years (2014-15 to 2018-19).

\begin{tabular}{|c|c|c|}
\hline Alternatives (NBFC-MFIs) [Abbreviations] & Relative closeness $\left(\boldsymbol{R}_{\boldsymbol{i}}\right)$ & Rank \\
\hline Adhikar & 0.45076385 & 9 \\
\hline Agora & 0.38509633 & 17 \\
\hline Arohan & 0.55196795 & 2 \\
\hline ASA & 0.47208745 & 5 \\
\hline Asomi & 0.42883900 & 13 \\
\hline Belstar & 0.48278652 & 18 \\
\hline BWDA & 0.35099809 & 15 \\
\hline Chaitanya & 0.41409056 & 6 \\
\hline Fusion & 0.47136277 & 12 \\
\hline IDF & 0.43580953 & 3 \\
\hline Madura & 0.51042027 & 16 \\
\hline M-Power & 0.40241455 & 14 \\
\hline Pahal & 0.41894145 & 11 \\
\hline Prayas & 0.43581064 & \\
\hline Satin & 0.64760579 & \\
\hline Sonata & 0.45614652 & 1 \\
\hline Village fin & 0.44956153 & 0.46721362 \\
\hline
\end{tabular}

Source: Authors' calculations

\section{Findings and Discussion}

The present study ranked NBFC-MFIs registered with RBI on the basis of some financial performance criteria for a period of 5 years. For assigning the relative importance of each criterion in determining the performance, CRITIC method have been used and TOPSIS and IVTOPSIS have been applied for determining the ranks of each MFI over the years. As evident from Table 3, Satin Creditcare Network Limited (abbreviated as Satin) has ranked first for all the years from 2014 to 2018. So in this study, a financial performance benchmark has been set by this MFI. It is observed that while the position of Sonata Finance Private Limited (Sonata) has deteriorated from rank 2 in 2014-15 to rank 15 in 2018-19, ASA International India Microfinance Limited (ASA) has improved from rank 14 to 3 in the same span of 5 years. On the other hand, Arohan Financial Services Limited (Arohan) has improved its position and maintained the second rank for the last three consecutive years (2016-17 to 2018-19). Figure 1 depicts the variations in the closeness coefficients for different years (2014-15 to 2018-19).

The fluctuation in the ranks of the other MFIs for different years makes it difficult to gauge an overall ranking, on the basis of financial performance, for a cumulative period of 5 years. This task has been accomplished by using IV-TOPSIS method and the results displayed in Table 4 gives the picture of performance of these MFIs over the given time period. As expected, Satin is the top performer with the highest score of 0.65 while BWDA Finance Limited (BWDA) is the poorest performer with relative closeness score 0.35. Arohan and Madura Microfinance Limited (Madura) are the second and third highest performer, respectively. As observed from Table 3, Madura has maintained its rank between 3 and 4 and slightly deteriorated to rank 7 in 2018-19. This might attribute to the removal of two alternatives in that year. The overall ranking of the 18 
NBFC-MFIs are depicted in Figure 2 which clearly reflects the highest and lowest performing alternative.

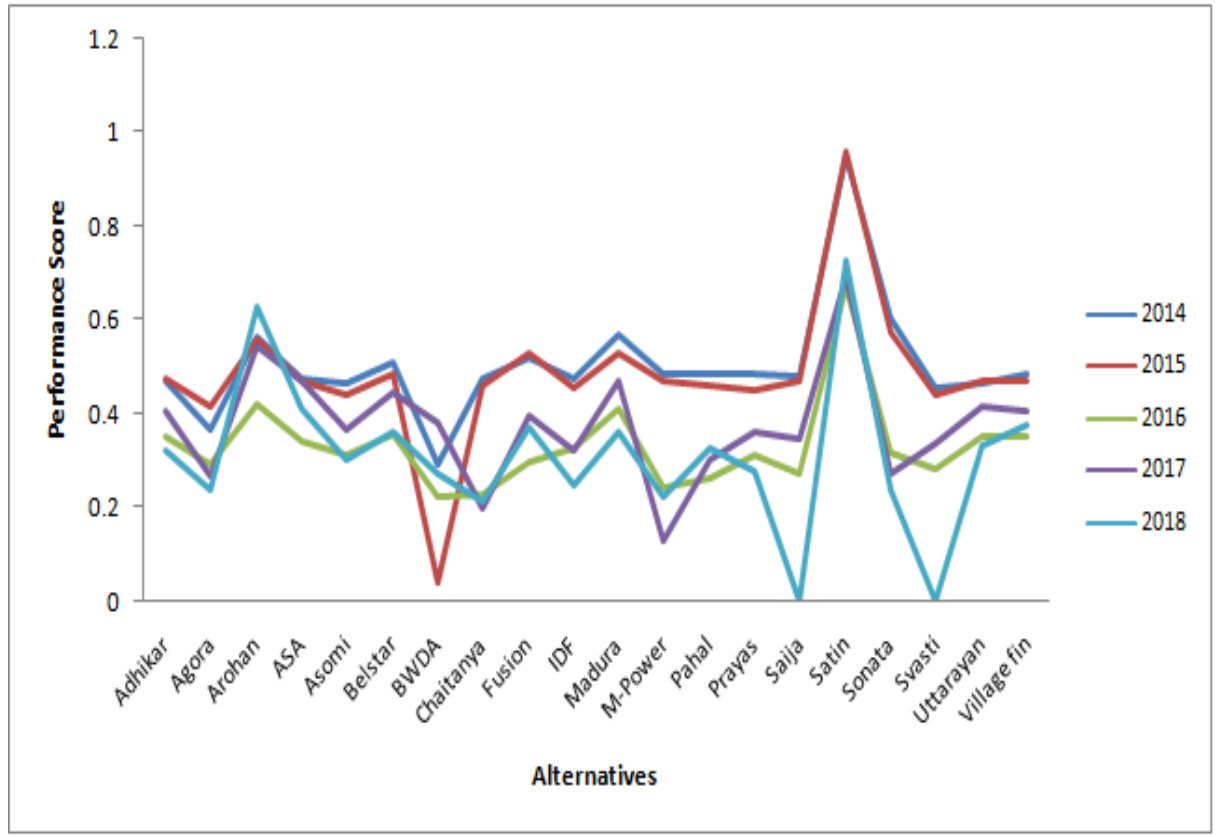

Figure 1. Variation in performance score.

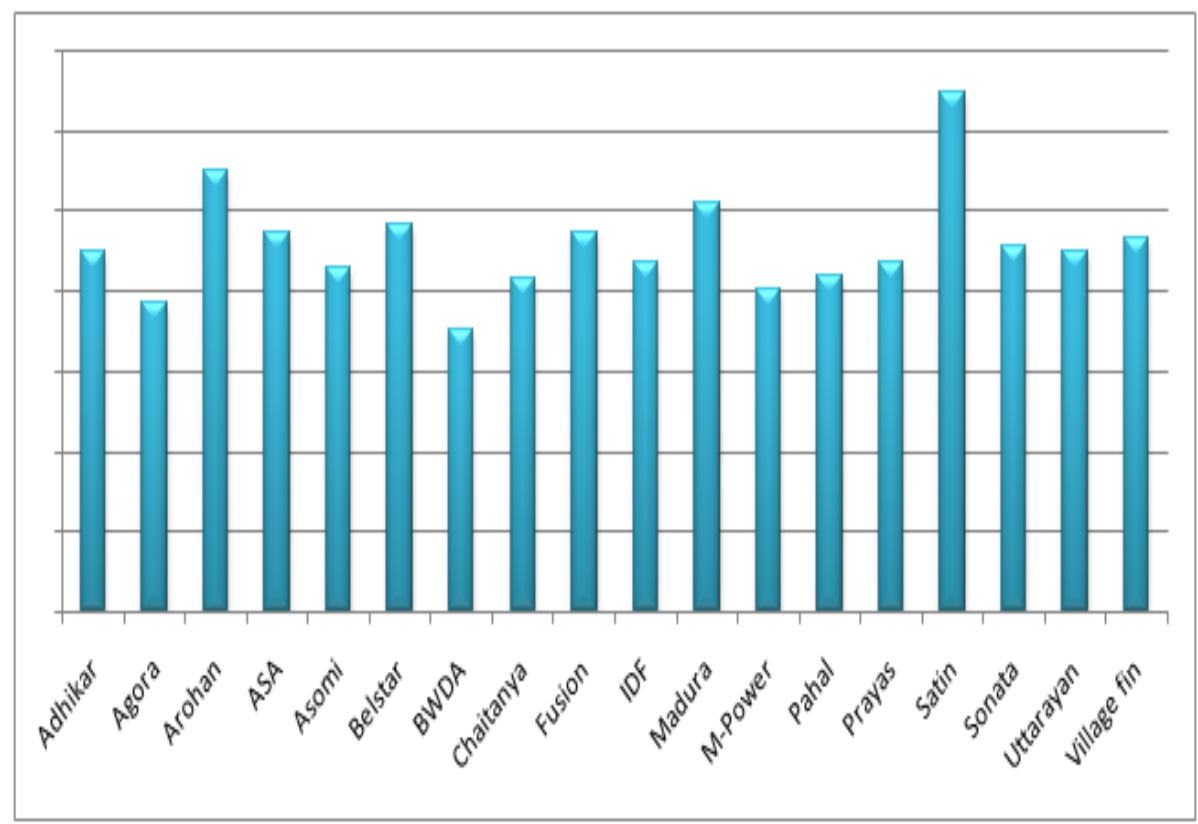

Figure 2. Ranking of NBFC-MFIs from 2014-15 to 2018-19. 


\subsection{Robustness Check}

The study has been checked for robustness through sensitivity analysis (Gupta et al., 2020). The analysis is done by altering the criteria weights in 5 sets and ranking the alternatives (NBFCMFIs) with the altered weights. The first set (user-defined) consist of the original weights determined by CRITIC. The altered weights from set 2-5 are obtained through creation of four scenarios. In the first scenario, all the criteria are considered equally important and assigned equal weights. In the second scenario, all the performance measures outreach, financial sustainability, quality and efficiency (See Table 1) are given equal importance and weights of each criteria under the performance measures are thus allocated accordingly. The third scenario consists in interchanging high criteria weights with low criteria weights and in the last scenario the weights of two of the most important criteria are reduced by 3 percent each and that of three least important ones are increased by 2 percent each. Table 5 shows the 5 different sets of criteria weights and the ranking obtained from the altered weights are depicted in Table 6.

The results of sensitivity analysis from Table 6 show there is not much change in the ranks for most of the alternatives after altering weights. Satin, Agora and Madura continue to be the top three rankers for all sets of weights and same is for the worst ranker BWDA. The results of sensitivity analysis are clearly portrayed in Figure 3.

Table 5. Criteria weights in sensitivity analysis.

\begin{tabular}{|c|c|c|c|c|c|c|c|}
\hline & $\mathbf{P}_{\mathbf{1}}$ & $\mathbf{P}_{\mathbf{2}}$ & $\mathbf{P}_{\mathbf{3}}$ & $\mathbf{P}_{\mathbf{4}}$ & $\mathbf{P}_{\mathbf{5}}$ & $\mathbf{P}_{\mathbf{6}}$ & $\mathbf{P}_{\mathbf{7}}$ \\
\hline Set 1 & 0.29 & 0.10 & 0.11 & 0.18 & 0.10 & 0.12 & 0.10 \\
\hline Set 2 & 0.143 & 0.143 & 0.143 & 0.143 & 0.143 & 0.143 & 0.143 \\
\hline Set 3 & 0.25 & 0.125 & 0.125 & 0.25 & 0.083 & 0.083 & 0.083 \\
\hline Set 4 & 0.10 & 0.12 & 0.11 & 0.10 & 0.18 & 0.10 & 0.29 \\
\hline Set 5 & 0.23 & 0.14 & 0.11 & 0.12 & 0.14 & 0.12 & 0.14 \\
\hline
\end{tabular}

Source: Authors' calculations

Table 6. Rank of NBFC-MFIs with sensitivity analysis.

\begin{tabular}{|c|c|c|c|c|c|}
\hline Alternatives (NBFC-MFIs) [Abbreviations] & Set 1 & Set 2 & Set 3 & Set 4 & Set 5 \\
\hline Adhikar & 9 & 7 & 7 & 7 & 8 \\
\hline Agora & 17 & 17 & 17 & 17 & 17 \\
\hline Arohan & 2 & 2 & 2 & 2 & 2 \\
\hline ASA & 5 & 5 & 5 & 5 & 5 \\
\hline Asomi & 13 & 13 & 13 & 13 & 13 \\
\hline Belstar & 4 & 4 & 4 & 4 & 4 \\
\hline BWDA & 18 & 18 & 18 & 18 & 18 \\
\hline Chaitanya & 15 & 15 & 15 & 15 & 15 \\
\hline Fusion & 6 & 12 & 9 & 12 & 7 \\
\hline IDF & 12 & 9 & 12 & 9 & 11 \\
\hline Madura & 3 & 3 & 3 & 3 & 3 \\
\hline M-Power & 16 & 16 & 16 & 16 & 16 \\
\hline Pahal & 14 & 14 & 14 & 14 & 14 \\
\hline Prayas & 11 & 10 & 11 & 11 & 12 \\
\hline Satin & 1 & 1 & 1 & 1 & 1 \\
\hline Sonata & 8 & 11 & 10 & 10 & 10 \\
\hline Uttarayan & 10 & 8 & 8 & 8 & 9 \\
\hline Village fin & 7 & 6 & 6 & 6 & 6 \\
\hline
\end{tabular}

Source: Authors' calculations 


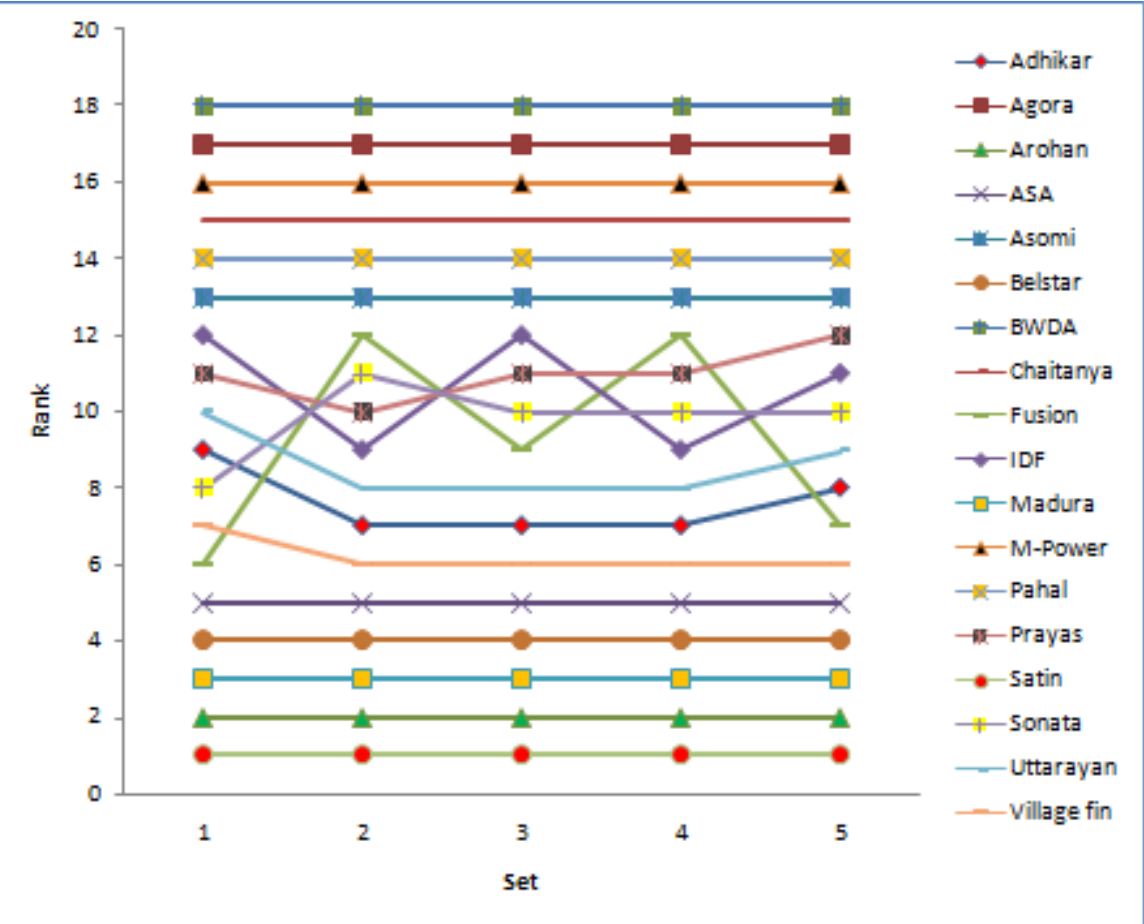

Figure 3. Sensitivity analysis.

\section{Conclusions}

The paper is an attempt at analyzing the performance of a sample of NBFC-MFIs. The results of TOPSIS clearly show Satin Creditcare Network Limited as the best performer for all individual years as well as for the combined 5 years period. However, the performance of other MFIs was fluctuating over the years. The IV-TOPSIS results reveal the financial performance for the cumulative 5 years period and portray BWDA Finance Limited as the worst performer in 5 years. The results found in this study are not consistent with Sinha and Pandey (2019) though we can argue that the study used different sample of MFIs as well as different performance indicators and methodology. However, in this study sensitivity analysis has been conducted for robustness test and it has been found that most of the NBFC-MFIs had the same rank for different sets of criteria weights. This study can be considered as a scenario which highlights the performance of microfinance sector. The methodology can be applied by organizations in accessing their performance as well as help funders to have a view on the financial performance of the selected MFIs.

The major limitation of this study lies in the small sample of MFIs due to the absence of annual financial results and hence missing data in the MIX database for a considerable number of NBFC-MFIs. This resulted in choosing only 20 NBFC-MFIs for this study out of 96 listed by RBI. Hence generalization of results for the whole sector needs to be done cautiously. However, the study used objective weighing method and hence free from personal bias in analyzing performance of the MFIs. Future researchers may attempt to select more MFIs to compare the results as well as include more financial performance pointers to have more generalized conclusion. 
Conflict of Interest

The authors confirm that there is no conflict of interest to declare for this publication.

\section{Acknowledgments}

This research did not receive any specific grant from funding agencies in the public, commercial, or not-for-profit sectors. The authors would like to thank the editor and anonymous reviewers for their comments that help improve the quality of this work

\section{References}

Abrar, A., Hasan, I., \& Kabir, R. (2021). Finance-growth nexus and banking efficiency: The impact of microfinance institutions. Journal of Economics and Business, 114, 105975.

Ambarkhane, D., Singh, A.S., \& Venkataramani, B. (2018). Measuring total factor productivity change of microfinance institutions in India using malmquist productivity index. Indian Growth and Development Review, 12(1), 105-130.

Amile, M., Sedaghat, M., \& Poorhossein, M. (2013). Performance evaluation of banks using fuzzy AHP and TOPSIS, case study: state-owned banks, partially private and private banks in Iran. Caspian Journal of Applied Sciences Research, 2(3), 128-138.

Awaworyi Churchill, S. (2020). Microfinance financial sustainability and outreach: is there a trade-off? Empirical Economics, 59(3), 1329-1350.

Bardhan, A.K., Nag, B., Mishra, C.S., \& Tarei, P.K. (2021). An integrated framework for analysing performance indicators of Indian microfinance institutions: a multi-stakeholder perspective. Benchmarking: An International Journal. https://doi.org/10.1108/BIJ-09-2020-0470

Bartual Sanfeliu, C., Cervelló Royo, R., \& Moya Clemente, I. (2013). Measuring performance of social and non-profit microfinance institutions (MFIs): An application of multicriterion methodology. Mathematical and Computer Modelling, 57(7-8), 1671-1678.

Bedecarrats, F., Angora, R.W., \& Lapenu, C. (2009). Is social performance profitable? The relationship between social and financial performance in microfinance. MicroBanking Bulletin, 19(1), 22-29.

Cervelló-Royo, R., Guijarro, F., \& Martinez-Gomez, V. (2019). Social performance considered within the global performance of microfinance institutions: A new approach. Operational Research, 19(3), 737755.

Chattopadhyay, M., \& Mitra, S.K. (2017). Applicability and effectiveness of classifications models for achieving the twin objectives of growth and outreach of microfinance institutions. Computational and Mathematical Organization Theory, 23(4), 451-474.

De Crombrugghe A, Tenikue, M., \& Sureda, J. (2008). Performance analysis for a sample of microfinance institutions in India. Annals of Public and Cooperative Economics, 79(2), 269-299.

Cull, R., Harten, S., Nishida, I., Rusu, A.B., \& Bull, G. (2015). Benchmarking the financial performance, growth, and outreach of greenfield MFIs in Africa. Emerging Markets Review, 25, 92-124.

Demirgüç-Kunt, A., Klapper, L.F., \& Singer, D. (2013). Financial inclusion and legal discrimination against women: Evidence from developing countries. World Bank Policy Research Working Paper, 6416, 1-47. http://dx.doi.org/10.1596/1813-9450-6416

Diakoulaki, D., Mavrotas, G., \& Papayannakis, L. (1995). Determining objective weights in multiple criteria problems : The critic method. Computers \& Operations Research, 22(7), 763-770.

Dutta, P., \& Das, D. (2014). Indian MFI at crossroads: Sustainability perspective. Corporate Governance (Bingley), 14(5), 728-748. 
Ferro-Luzzi, G., \& Weber, S. (2006). Measuring the performance of microfinance institutions. Haute École De Gestion De Genève, 1-17. https://doi.org/10.2139/ssrn.918750

Ghose, B., Paliar, S.J., \& Mena, L. (2018). Does legal status affect performance of microfinance institutions?: Empirical evidence from India. Vision- The Journal of Business Perspective, 22(3), 316328.

Ghouse, S.M. (2019). Micro finance - A catalyst in accelerating the growth of indian rural economy. International Journal of Recent Technology and Engineering, 8(3), 6010-6012.

Gümrah, A. (2016). Measuring the performance of participation banks by topsis method: Turkey and Malaysia cases. International Journal of Business and Management Studies, 5(1), 211-218.

Gupta, S., Mathew, M., Gupta, S., \& Dawar, V. (2020). Benchmarking the private sector banks in India using MCDM approach. Journal of Public Affairs, 21(2), 1-6.

Hermes, N., \& Hudon, M. (2018). Determinants of the performance of microfinance institutions: A systematic review. Journal of Economic Surveys, 32(5), 1483-1513.

Hermes, N., \& Lensink, R. (2007). The empirics of microfinance: What do we know? The Economic Journal, 117(517), 1-10.

Ho, C.T., \& Wu, Y.S. (2006). Benchmarking performance indicators for banks. Benchmarking: An International Journal, 13(1-2), 147-159.

Jahanshahloo, G.R., Hosseinzadeh Lotfi, F., \& Davoodi, A.R. (2009). Extension of TOPSIS for decisionmaking problems with interval data: Interval efficiency. Mathematical and Computer Modelling, 49(56), 1137-1142.

Hwang, C.L., \& Yoon, K. (1981). Multiple attribute decision- making methods \& applications. Taylor \& Francis Group, New York.

Lacalle-Calderón, M., Chasco, C., Alfonso-Gil, J., \& Neira, I. (2015). A comparative analysis of the effect of aid and microfinance on growth. Canadian Journal of Development Studies, 36(1), 72-88.

Louis, P., Seret, A., \& Baesens, B. (2013). Financial efficiency and social impact of microfinance institutions using self-organizing maps. World Development, 46, 197-210.

Mathew, M., \& Thomas, J. (2019). Interval valued multi criteria decision making methods for the selection of flexible manufacturing system. International Journal of Data and Network Science, 3(4), 349-358.

Mushtaq, R., \& Bruneau, C. (2019). Microfinance, financial inclusion and ICT: implications for poverty and inequality. Technology in Society, 59, 101154.

Mustafa, A.K.A., \& Saat, M.M. (2013). Microfinance institutions performance measurement: Introducing a new performance measurement framework. Middle East Journal of Scientific Research, 15(11), 16181628.

Nadiya, M., Olivares-Polanco, F. \& Ramanan, T.R. (2012). Dangers in mismanaging the factors affecting the operational self-sustainability (OSS) of Indian microfinance institutions (MFIs): an exploration into Indian microfinance crisis. Asian Economic and Financial Review, 2(3), 448-462.

Navajas, S., Schreiner, M., Meyer, R.L., Gonzalez-Vega, C., \& Rodriguez-Meza, J. (2000). Microcredit and the poorest of the poor: Theory and evidence from Bolivia. World Development, 28(2), 333-346.

Ngong, C.A., Thaddeus, K.J., \& Onwumere, J.U.J. (2021). Microfinancial inclusion nexus poverty alleviation: the case of Nigeria. Journal of Economic and Administrative Sciences. https://doi.org/10.1108/jeas-08-2020-0147

Pal Narwal, K., Pathneja, S., \& Kumar Yadav, M. (2015). Performance analysis of banks and microfinance institutions in India. International Journal of Management and Business Research, 5(1), 9-18. 
Quayes, S., \& Joseph, G. (2017). Legal systems and performance of microfinance institutions. International Review of Applied Economics, 31(3), 304-317.

Rosenberg, R. (2009). Measuring results of microfinance institutions. Consultative Group to Assist the Poor, June. 1-25.

Roszkowska, E. (2011). Multi-criteria decision making models by applying the TOPSIS method to crisp and interval data. Multiple Criteria Decision Making/University of Economics in Katowice, 6(1), 200230.

Saad, M., Taib, H.M., \& Bhuiyan, A.B. (2019). Re-evaluating sustainability of microfinance institutions by using topsis. Humanities and Social Sciences Reviews, 7(2), 581-589.

Saunders, M., Mann, R., \& Smith, R. (2007). Benchmarking strategy deployment practices. Benchmarking: An International Journal, 14(5), 609-623.

Shafi, M., \& Reddy, M.R. (2017). Financial performance of microfinance institutions in India: A study based on outreach and profitability. International Journal of Applied Business and Economic Research, 15(9), 221-231.

Shih, H.S., Shyur, H.J., \& Lee, E.S. (2007). An extension of TOPSIS for group decision making. Mathematical and Computer Modelling, 45(7), 801-813.

Sinha, R.P., \& Pandey, P. (2019). Efficiency of microfinance institutions in India: A two-stage DEA approach. International Journal of Rural Management, 15(1), 49-77.

Yaron, J. (1994). What makes rural finance institutions successful? The World Bank Research Observer, 9(1), 49-70. 